\title{
A cross-sectional study: Exposure, Effect and Awareness of second-hand smoking in the central region of Saudi Arabia
}

\section{Gigi Sam*, Gadah Aysh Zaid Aweesh Alotaibi, Ghadah Rashed Gazi Alotaibi, Hend Ahmad Hosain Altharwi, Waad Fahad Mohammmad Helal Alotaibi}

\author{
College of pharmacy, Shaqra University, Al-Dawadimi; Saudi Arabia
}

Received: 02 November,2019

Accepted: 17 December,2019

*Correspondence to:

Mrs. Gigi Sam,

Email: gigipharma@gmail.com

Copyright: (c) the author(s), publisher and licensee Indian Academy of Pharmacists. This is an open-access article distributed under the terms of the Creative Commons Attribution NonCommercial License, which permits unrestricted noncommercial use, distribution, and reproduction in any medium, provided the original work is properly cited.

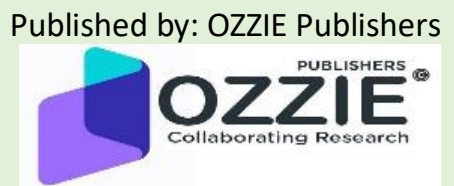

\begin{abstract}
Background: Second-hand smoking (SHS) has been strongly associated with poor health outcomes, higher risk of lung cancer in adults, increased frequency of respiratory disease in children. This study was aimed to estimate the prevalence of exposure, investigate the possible associated risk factors and to assess the knowledge and awareness towards SHS. Method: A cross-sectional study was conducted and data's pertaining to sociodemographic characteristics, sources of exposure, respiratory symptoms and awareness were collected using a self-administered questionnaire and evaluated. Results: Nearly 72.98\% participants reported that maximum exposure to second-hand smoke were in Estirah (social club) followed by Internet cafe (35.48\%), Park (22.98\%), Shopping malls (22.18\%), Playground (19.76\%), College (8.87\%) and Restaurants (7.26\%). Parental smoking had a major risk of exposure inside the home $(30.24 \%)$ and friends outside (28.63\%) the home. The risk of SHS was less common with people who had adequate knowledge and also with educated parents. A significant association was found between SHS exposure and chronic phlegm (42.74\%), dyspnoea (41.13\%) chronic cough (27.96\%), wheezing (23.79\%). The knowledge and awareness among people on SHS were adequate though the practices were poor. $76.21 \%$ of the parents reported that SHS exposure made their child's health worse and $72.58 \%$ opted for smoke-free public places while $26.21 \%$ participants allowed visitors to smoke in their house. Conclusion: Hence, it is very important to develop and propagate effective measures to promote smoke-free homes and public places. Health education programs should also address the more complex problem of motivating people to change their attitudes.
\end{abstract}

Keywords: Second-hand smoking exposure (SHS), awareness, respiratory Symptoms, smoke-free.

\section{INTRODUCTION}

Cigarette smoking is the major cause of preventable diseases, including cardiovascular disease, lung cancer, and chronic obstructive pulmonary disease. Involuntary exposure to environmental tobacco smoke also carries many hazards. Exposure to cigarette smoke or second-hand smoking has been associated with a higher risk of lung cancer in adults, and with increased frequency of respiratory infections and symptoms in children [1].

Second-hand smoking is defined as the inhalation of tobacco smoke by non-smokers against their will or as being the involuntary exposure to tobacco smoke [2]. Passive smoking is the inhalation of smoke, called second-hand smoke (SHS), or environmental tobacco smoke (ETS), by persons other than the intended "active" smoker [3]. Second-hand smoke consists of $15 \%$ mainstream smoke and $85 \%$ side stream smoke.

"Mainstream smoke" is the smoke discharged by expiration after being filtered through the smoker's lungs [4]."Side stream smoke" is the smoke that goes directly into the air from a burning cigarette, or cigar while it rests in the ashtray or is held by the smoker. In particular, the side stream smoke contains many highly concentrated toxic chemicals or carcinogens, which may be more harmful than mainstream smoke [5].

Studies have reported that non-smokers with SHS exposure have a 2.1 times greater risk of developing lung cancer compared to those without SHS exposure [6], while they have a 1.6 and 1.4 times greater risk of developing cardiovascular disease [7] and stroke [8], respectively. Second-hand tobacco smoke can spread from one room to another within a building, even if doors to the smoking area are closed. Toxic chemicals from second-hand tobacco smoke contamination persist well beyond the period of active smoking, and then cling to rugs, curtains, clothes, food, furniture and other materials [9]. These toxins can remain in a room weeks and months after someone has smoked there even if windows are opened or fans or air filters are used $[9,10]$. Filters can become a source of deposited chemicals that are then recycled back into the air of a room 
rather than removed. Tobacco toxins that build up over time, coating the surfaces of room elements and materials and smokers' belongings, are sometimes referred to as "thirdhand smoking" $[11,12]$. However, it is three to four times more toxic per gram of particulate matter than mainstream tobacco smoke, and the toxicity of side stream smoke is higher than the sum of the toxicities of its constituents [4].

Since the 1970s, there is increasing evidence that not only is active smoking a risk factor of respiratory diseases, but also second-hand smoking. In the Kingdom of Saudi Arabia (KSA), a national study conducted in 2008 reported a smoking prevalence of $36 \%$ and $3 \%$ among male and female adults, respectively $[13,14]$.

\section{Materials and Methods \\ (i) Study Design:}

A cross-sectional survey was performed from September 2016 to January 2017 to study factors associated with second-hand smoking exposure, its effect, knowledge and awareness of second-hand smoking among the people living in the central parts of Saudi Arabia which includes Riyadh, Dawadimi, Sajar, Al-Burood. Participants of the study included males and females of the age 13 years and above with an ability to read and understand Arabic.

\section{(ii) Data collection:}

A self-administered questionnaire was employed to assess the exposure, effect of exposure, knowledge and awareness towards second-hand smoking. A 35-items questionnaire divided into 4 major sections written in English language was used in this study. The questionnaire was then translated into Arabic by a language expert, which would be easily understood and responded even by common people. Data's was collected by student researchers pursuing 3rd year of pharm.D programme in college of pharmacy, Shaqra University, Al-Dawadimi, Saudi Arabia.

The questionnaire consisted of a mixture of qualitative and quantitative questions besides demographic information. Questionnaires were distributed to the non-smokers in Riyadh, Dawadimi, Sajar and Al-Burood. The respondents completed the questionnaires and submitted to the concerned student researchers.

\section{RESULTS AND DISCUSSION}

In the current study of second-hand smoking 248 candidates actively participated in the survey out of which $31 \%$ was male and $69 \%$ female. Exposure in Estirah (social club) was the most common place reported by $72.98 \%$, followed by exposure in the Internet cafe (35.48\%), Park (22.98\%), Shopping malls $(22.18 \%)$, Playground (19.76\%), College $(8.87 \%)$ and Restaurants $(7.26 \%)$.The datas are shown in fig1.
Among the sources of exposure, the highest were from parental smoking (30.24\%) followed by friends (28.63\%) Siblings (18.55\%).

Participants were specifically asked if they had ever been diagnosed with asthma or whether they experienced a range of respiratory symptoms. Standard questions about the wheeze, dyspnoea, chronic cough and chronic phlegm were included and among the total sample $42.74 \%$ were affected with chronic phlegm followed by $41.13 \%$ with dyspnoea, $27.96 \%$ with chronic cough and $23.79 \%$ with wheezing after exposure to second-hand smoking (fig-2).

Out of the total participants, $27 \%$ had three respiratory symptoms where as all the other participants had at least one symptoms specified on the questionnaire. The result of of the effect of SHS exposure was normally distributed with a mean of 3.56 and SD of 1.63 and is shown in the fig-3.

The questionnaire also contained few questions to collect information if the public have knowledge and awareness about second-hand smoking.

However; despite of a different life-style and cultural back ground, there is adequate knowledge and awareness on SHS among Saudis. $76.21 \%$ of the parents reported that SHS made their child's health worse. $72.58 \%$ of the participants opted that public places should be smoke-free. $71.37 \%$ of them recommended for restriction of smoking in public places which would certainly deteriorate various respiratory illness and improve the quality of the people. $26.21 \%$ of the participants reported that they allow visitors to smoke in their house. (Table-1)

Out of the total participants, $75 \%$ had a positive awareness towards SHS exposure and its effects with a mean of 7.45 and SD of 1.325 (Fig-4). But still there exist ignorance and reluctance among the public on this aspect. Therefore, as a health care professionals, it is our prime responsibility to conduct health campaigns frequently emphasizing the extend of serious effects on non-smokers.

\section{CONCLUSION:}

The prevalence of SHS exposure was the highest in social club and source of exposure was greater in the home than outside. Two thirds of the participants reported that SHS made their child's health worse and all the participants had respiratory symptoms. Health campaigns should be extended to the school children encouraging them to defend their right to a smoke-free environment. Most people have knowledge of SHS but they are unaware of the extent of ill effects. Health education programs should address the more complex problem of motivating people to change their attitudes and ignorance.

What is already known about this subject:

- There is increasing evidence that not only is active smoking a risk factor of respiratory diseases, but also second-hand smoking.

- Most of the non-smokers are affected by respiratory related problems.

\section{What this study adds}

- The study reveals that many of the people exposed to SHS were teenagers who suffered serious deteriorating effects on their health.

- Hence, it was found important to focus the effects of secondhand smoking on this age group and highlight the possible preventive measures that can be taken.

- Though, people knew the ill effects of SHS they are reluctant to execute their role towards smoke free environment and therefore health education programs must play a very active role in eradicating smoking.

- Effective regulatory approaches, which have been proposed and implemented regarding SHS, has to be checked periodically for its ........tin... 


\section{Footnotes}

Contributors: GS developed the study design and prepared questionnaire. SPS performed the statistical analysis. GS wrote the first and successive drafts of the manuscript. Other authors effectively collected the required datas after translating the questionnaire in Arabic language which could

\section{REFERENCES}

1. Mohammad-Reza Masjedi et al. Effects of passive smoking on the pulmonary function of adults. Thorax 1990;45: 27-31. 2.

http://www.medicinenet.com/script/main/art.asp?articlekey= 13423

3. https://en.wikipedia.org/wiki/Passive_smoking

4. Schick, S.; Glantz, S. Philip Morris. Toxicological experiments with fresh sidestream smoke: more toxic than mainstream smoke. Tob.Control 2005, 14: 396-404.

5. Eun-Kyung Kim, Jina Choo. Secondhand Tobacco Smoke Exposure and Associated Factors among College Students on Campus and in the Home: A Preliminary Study. International Journal of Environmental Research and Public Health, 2012 ,9(1):212-222.

6. Lam, T.H.; Kung, I.T.; Wong, C.M.; Lam, W.K.; et al. Smoking, passive smoking and histological types in lung cancer in Hong Kong Chinese women. Br. J. Cancer 1987, 56: 673-678.

7. Humble, C.; Croft, J.; Gerber, A.; Casper, M.; Hames, C.G.; Tyroler, H.A. Passive smoking and 20-year cardiovascular disease mortality among nonsmoking wives, Evans County, Georgia. Am. J. Public Health 1990, 80: 599-601. be understood by the public. The corresponding author attests that all listed authors meet authorship criteria and that no others meeting the criteria have been omitted.

Funding: This work was not supported by any external grants or funding.

Ethical approval: Not required.

8. Glymour, M.M.; Defries, T.B.; Kawachi, I.; Avendano, M. Spousal smoking and incidence of first stroke: the Health and Retirement Study. Am. J. Prev. Med. 2008, 35: 245-248.

9. Stanton A. Glantz, PhD; William W. Parmley, MD, Passive Smoking and Heart Disease Mechanisms and Risk, JAMA. 1995;273(13):1047-1053.

10. Singer BC et al. Gas-phase organics in environmental tobacco smoke. Effects of smoking rate,ventilation, and furnishing level on emission factors. Environmental Science and Technology, 2002,36:846-853.

11. Protect people from smoke-World Health Organisation report on the global tobacco epidemic,2009.From:http://www.who.int/tobacco/mpower/20 09/c_gtcr_protect_people_tobacco_smoke.pdf12.

12. Winickoff JP et al. Beliefs about the health effects of "thirdhand" smoke and home smoking bans.Pediatrics, 2009, 123:74-79.

13. A. M. Albedah, M. K. Khalil et al. "Use of the target group index survey to evaluate the cigarette smoking profile in Saudi Arabia,” Saudi Medical Journal 2011, vol. 32(10):1055-1059. 14. Abdulmohsen H. Al-Zalabani, Soliman M. Amer;et al. Second-Hand Smoking among Intermediate and Secondary School Students in Madinah, Saudi Arabia. Biomed Res Int. 2015: 672393.

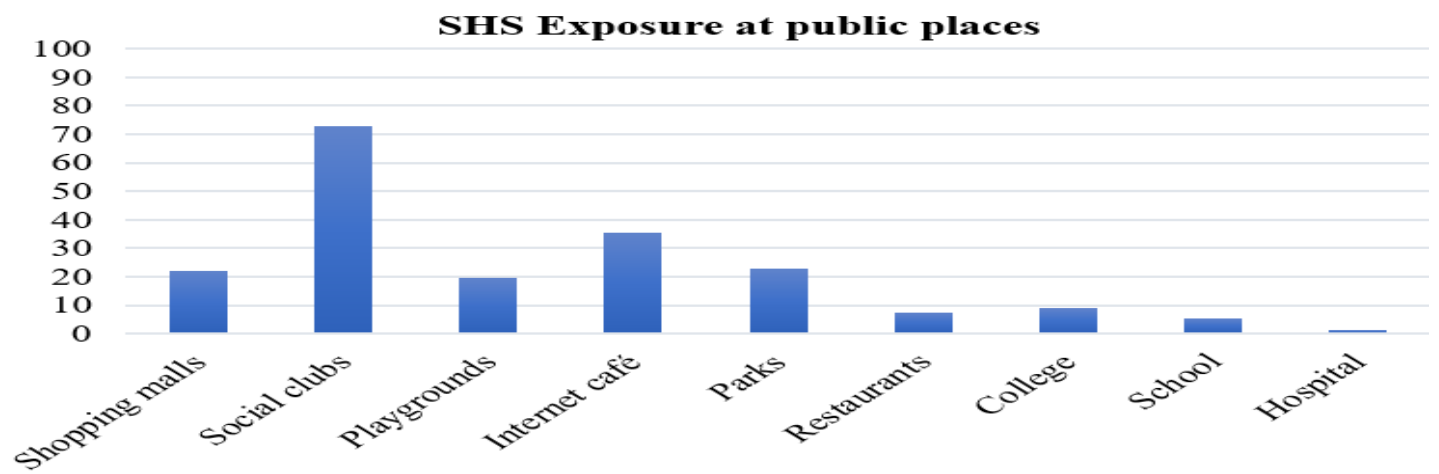

Fig-1: SHS Exposure at public places

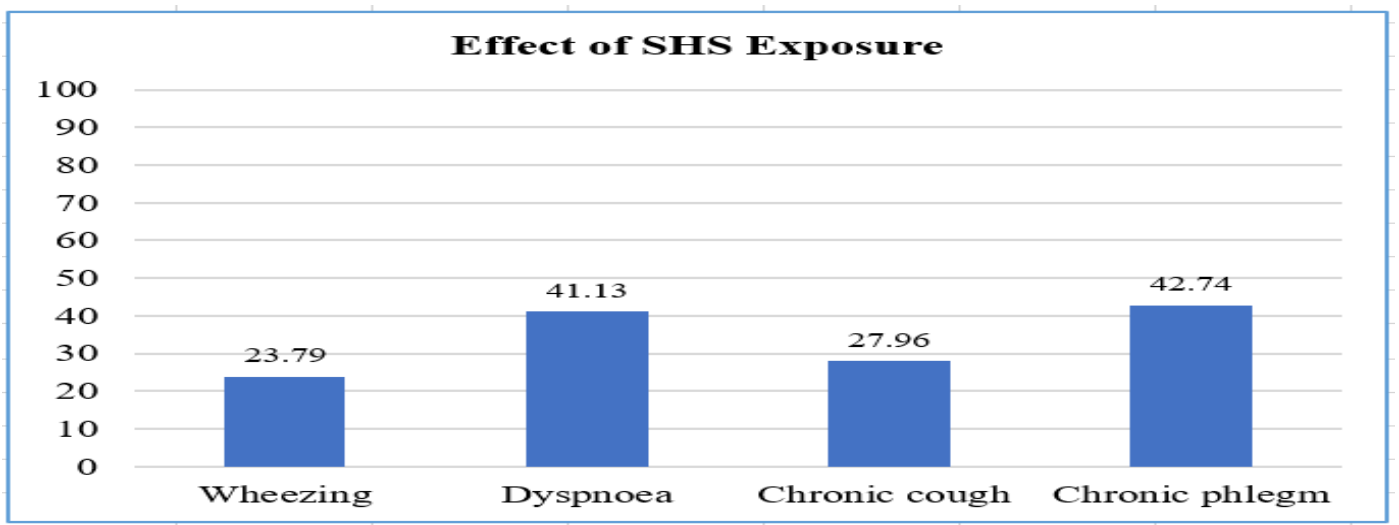

Fig-2 : Effects of SHS Exposure 


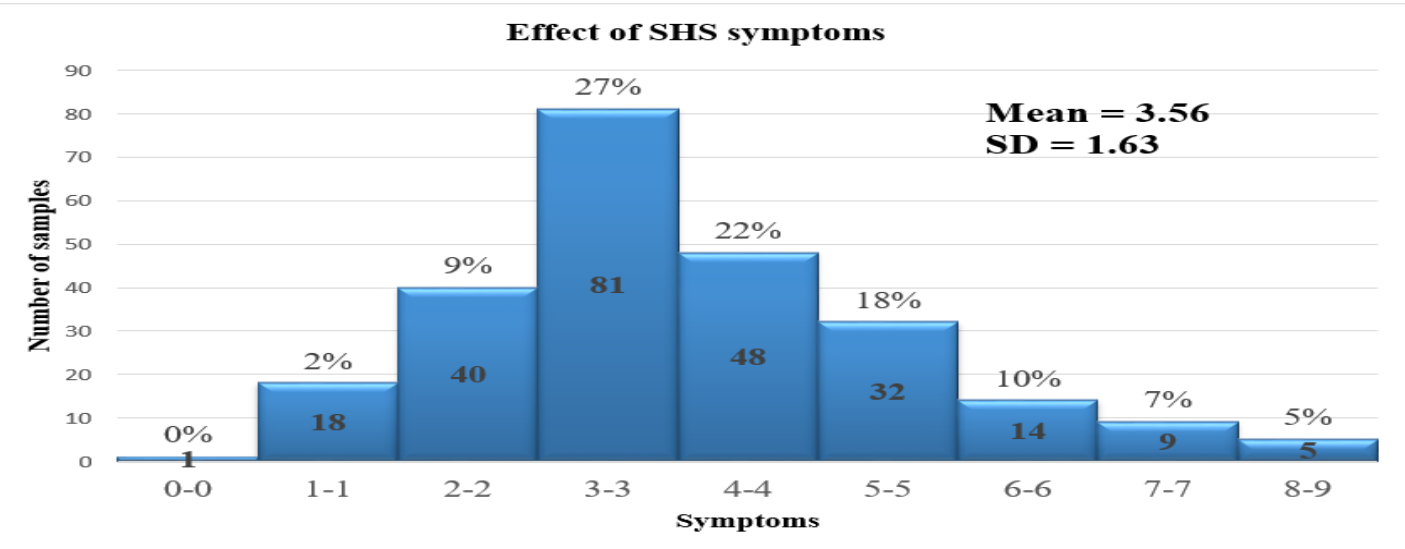

Fig-3 : Effects of Respiratory symptoms

(X-axis corresponds to the number of questions related to effects of respiratory symptoms).

\begin{tabular}{|l|l|l|}
\hline Question & \multicolumn{1}{|c|}{$\begin{array}{c}\text { Knowledge and awareness of SHS } \\
\text { \% of positive } \\
\text { response }\end{array}$} \\
\hline 1 & Smoking is dangerous for non-smoker's health & $86.29 \%$ \\
\hline 2 & Children exposed to tobacco smoke have more illnesses & $79.03 \%$ \\
\hline 3 & Exposure to tobacco smoke can cause lung cancer in non-smokers & $63.31 \%$ \\
\hline 4 & Public places should be smoke-free & $72.58 \%$ \\
\hline 5 & Smoke from other people's cigarettes is harmful for me & $68.95 \%$ \\
\hline 6 & Smoking should be banned in all public places & $71.37 \%$ \\
\hline 7 & Passive smoking makes my child's health worse & $76.21 \%$ \\
\hline 8 & I let visitors smoke in my home & $26.21 \%$ \\
\hline 9 & I distance myself and will not be exposed to smoke & $71.37 \%$ \\
\hline 10 & Tried to prevent smoking near me & $80.65 \%$ \\
\hline
\end{tabular}

Table-1: Knowledge And Awareness Of SHS

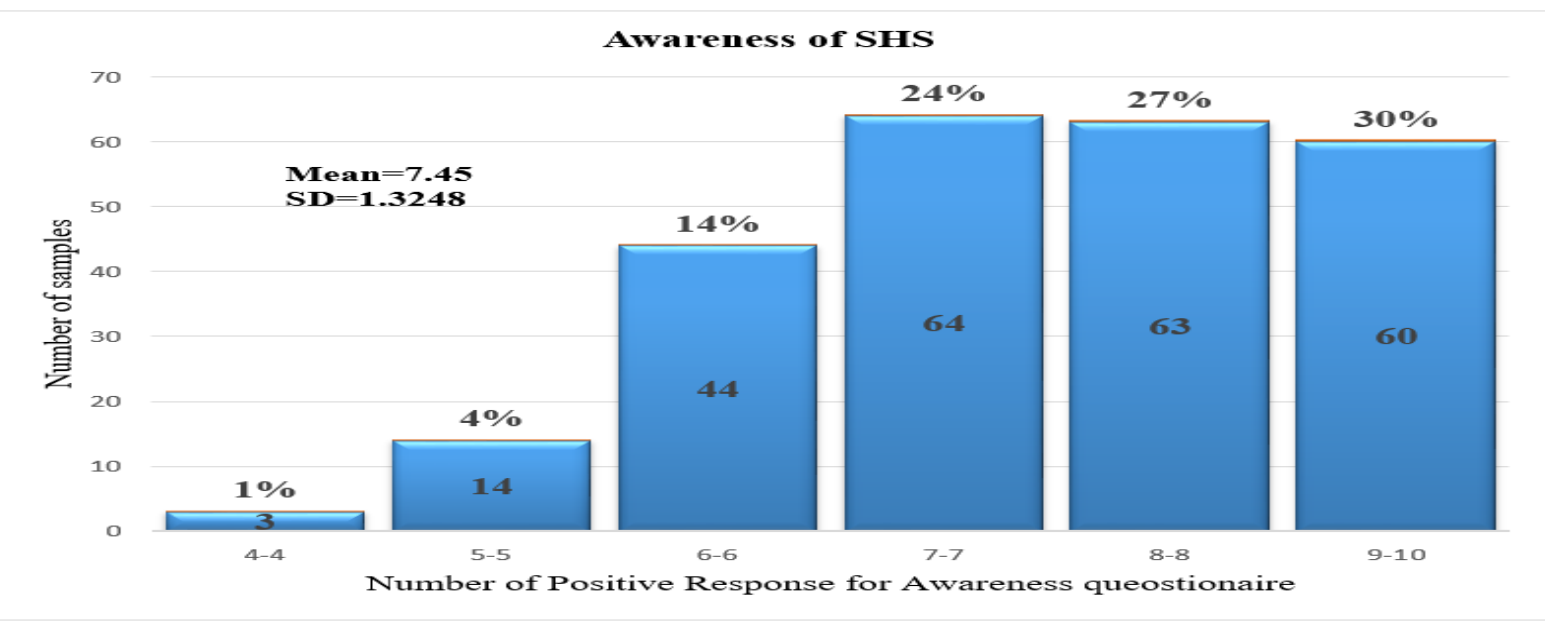

Fig-4: Knowledge and awareness of SHS

Cite article as: Sam G, GAZA Alotaibi, Alotaibi GRG, Altharwi HAH, Alotaibi WFMH. A cross-sectional study: Exposure, Effect and Awareness of second-hand smoking in the central region of Saudi Arabia. Res Pharm Healt Sci. 2019;5(4):218-221. doi: https://doi.org/10.32463/RPHS.2019.v05i04.05 